\title{
Assessment of EGM2008 using GPS/levelling and free-air gravity anomalies over Nairobi County and its environs
}

\author{
Patroba Achola Odera \\ Department of Geomatic Engineering and Geospatial Information Systems, Jomo Kenyatta University \\ of Agriculture and Technology, P.O BOX 62000-00200 Nairobi, Kenya, \\ podera@jkuat.ac.ke
}

DOI: $\underline{\text { htp: }: / / d x . \text { doi.org/10.4314/sajg.v5il.2 }}$

\begin{abstract}
The performance of Earth Gravitational Model 2008 (EGM2008) is evaluated over Nairobi County and its environs using GPS/levelling and free-air gravity anomalies. The data used include 18 GPS/levelling and 97 gravity points. The heights in Kenya are referred to the mean sea level and they are generally considered as orthometric heights. Hence the height anomalies obtained from tide-free EGM2008 model are converted to geoid undulations using a conversion model supplied with EGM2008. The standard deviation of the differences between EGM2008 implied and GPS/levelling geoid undulations at the 18 points is $\pm 11.6 \mathrm{~cm}$ while the standard deviation of the differences between EGM2008 implied free-air and observed free-air gravity anomalies at the 97 points is \pm 10.7 mGal. These results indicate a high potential for EGM2008 in geoid modelling over Kenya. An initial highresolution gravimetric geoid model over Kenya can be developed by combining EGM2008 and local gravity data sets.
\end{abstract}

Key words: EGM2008, geoid undulations, free-air gravity anomalies, GPS/levelling, Nairobi County and its environs

\section{Introduction}

The EGM2008 model is complete to spherical harmonic degree and order 2159, and contains additional coefficients extending to degree 2190 and order 2159. In addition, it is supplied with a conversion model complete to degree and order 2160 for converting height anomalies to geoid undulations (Pavlis et al., 2012). It represents the highest resolution to date of $5^{\prime} \times 5^{\prime}$ of arc (aprrox. 9 $\mathrm{km} \times 9 \mathrm{~km}$ ). Several authors have evaluated EGM2008 in different parts of the world (e.g. Huang and Véronneau, 2009; Claessens et al., 2009; Hirt et al., 2010; Pavlis et al., 2012; Featherstone and Olliver, 
2013; Odera and Fukuda, 2013; Abeho et al., 2014). Other assessment studies (25 in number) are presented in Newton's Bulletin (2009). Most of the comparative studies show that EGM2008 has made significant improvement over EGM96. However, such studies have not been carried out in Kenya.

EGM2008 is based on GRACE (Gravity Recovery and Climate Experiment) gravity field model ITG-GRACE03S (Mayer-Gürr, 2007). ITG-GRACE03S is a satellite only gravitational model complete to degree and order 180. Other data sets used in the development of EGM2008 include a global grid of $5^{\prime} \times 5^{\prime}$ gravity anomalies (based on high-resolution topographic data), altimetry-derived gravity data over the oceans and point terrestrial gravity data. Details of the above data sets can be found in Pavlis and Saleh, 2004, Pavlis et al., 2004, Pavlis et al., 2007, Pavlis et al., 2008; Andersen et al., 2010; Pavlis et al., 2012. These data sets are combined through an iterative least squares technique to obtain spherical harmonic coefficients up to degree 2190 and order 2159 (e.g. Pavlis et al., 2012).

An accurate geoid model is desirable for heighting purposes and other geophysical applications. Data from the recent satellite gravity missions such as CHAMP, GRACE and GOCE have revolutionised the determination of GGMs from space. The availability of many GGMs presents a good challenge. That is, how to integrate the available data sets to realise better solutions for geoid models at local, regional and global levels. Kenya can greatly benefit from the current high-resolution GGMs to develop a fairly accurate geoid model. Indeed Kenya is still in the process of developing a national geoid model for geodetic and geophysical applications. Gachari and Olliver, 1998 developed a gravimetric geoid model covering the Eastern Africa (Kenya, Uganda and part of Tanzania) using Ohio State University model 1991A (Rapp et al., 1991), combined with terrestrial gravity and satellite altimetry data. It is expected that the current GGMs would improve geoid modelling in Kenya.

This paper carries out an initial assessment of EGM2008 over Nairobi County and its evirons using observed free-air gravity anomalies and GPS/levelling geoid undulations. The model (EGM2008) is truncated at various spectral bands - 30 degrees interval between 0 to 180 degrees and 180 degrees interval between 180 to 2190 degrees. The paper also discusses implications of the assessment results for EGM2008 at different degrees and determines an optimal truncation for geoid medelling in Nairobi area and its environs and possibly Kenya. 


\section{Materials and Methods}

\subsection{Description of data sets}

Gravity observations in Kenya began around 1899 (Searle, 1970). Searle, 1970 describes gravity observations over Kenya from 1899 to 1967. Swain and Aftab Khan, 1978 give an elaborate description of a catalogue of gravity data and derived Bouguer anomaly maps for Kenya. This study used a catalogue of gravity data observed between 1955 and 1975 (Swain and Aftab Khan, 1977; Swain, 1979). This catalogue of gravity data contains gravity data observed by various companies and organisations/institutions e.g. Leicester University, Newcastle University, Overseas Geological Surveys, United Nations Geothermal Project, British Petroleum, Burmah Oil Trading and Chevron Overseas Petroleum. Gravity data sets observed after 1975 by petroleum companies are unfortunately scanty and isolated in format and distribution in addition to being not readily available for the current research. A compilation of such gravity data sets would improve geoid modelling and other geophysical applications in Kenya. Most of the Gravity measurements were made with LaCoste \& Romberg gravimeter and referred to Nairobi pendulum station based on IGSN71 datum. The accuracy of the gravity data ranges between \pm 1 to \pm 10 gu (Swain and Aftab Khan, 1977), which translates to \pm 0.1 to $\pm 1 \mathrm{mGal}$.

A geodetic levelling program for Kenya was proposed in 1947 but actual levelling was carried out between 1950 and 1958. A tidal station was constructed at Kilindini harbour in the Kenyan coastal town of Mombasa in 1931 and the mean sea level determined using tidal data recorded for a period of one year (Aseno, 1995). Levelling activities in Kenya started in 1949 with the construction of benchmarks. This was followed by actual precise levelling on main line from Mombasa running along the railway line. This line joined Uganda levelling network at Tororo and Buteba. A line from Kisumu to Sirari and another line from Mombasa to Vanga connected the Kenya datum to that of Tanzania (Aseno, 1995). The datum for height in Kenya is the mean sea level referred to a tide gauge at Kilindini Harbour in Mombasa. More details on the Kenyan levelling network can be found in Loxton, 1952. The permitted misclosure for the levelling network used in the current study varies from $3 \sqrt{K}$ (for primary network) to $8 \sqrt{K} \mathrm{~mm}$ (for secondary network), where $K$ is the distance in $\mathrm{km}$.

The study is limited to Nairobi County and its environs $\left(1.5^{\circ} \sim 1.1^{\circ} \mathrm{S}\right.$ and $\left.36.6^{\circ} \sim 37.2^{\circ} \mathrm{E}\right)$ due to lack of GPS/levelling data sets in other parts of Kenya. However, we note the ongoing GPS observations covering the entire country by Survey of Kenya. Once completed, the KENREF network would provide a good GPS coverage over Kenya. The GPS data used in this study was provided by 
Survey of Kenya. The GPS data was processed based on two IGS stations (San Marco in Malindi and KISM in Nairobi). The coordinates were computed using precise ephemeries and connected to ITRF94. SKI software was used for processing. It should be noted that KISM station was initially established from San Marco IGS station before the GPS campaign used in this study. In total, there are 97 gravity points and 18 GPS/levelling points in the area of study. Figure 1 shows a distribution of gravity and GPS/levelling data points in the area of study. The accuracy of GPS coordinates are given as, \pm 1 to $\pm 2 \mathrm{~cm}$ for horizontal position (ellipsoidal latitude and longitude) and \pm 2 to $\pm 4 \mathrm{~cm}$ for ellipsoidal height.

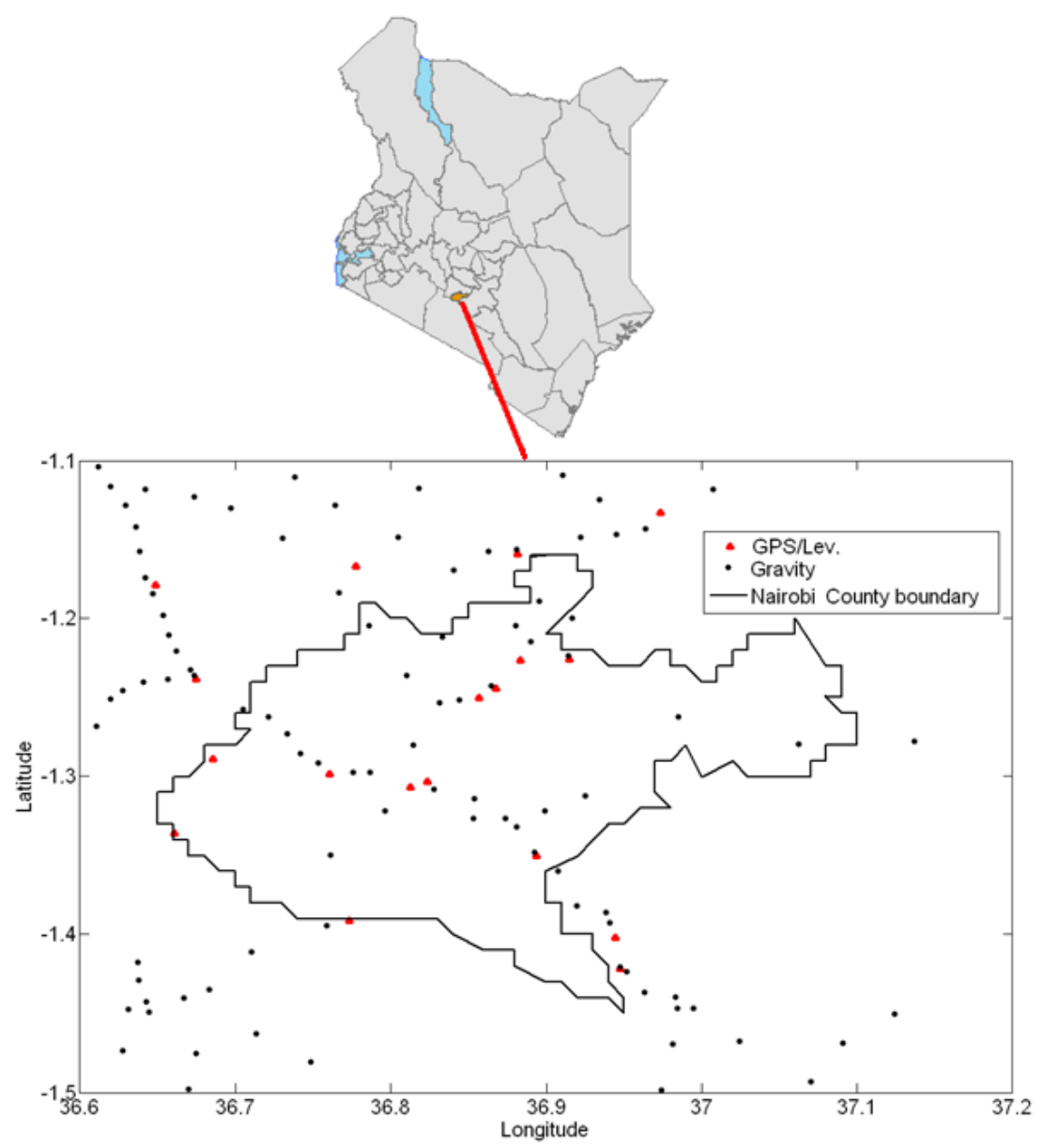

Figure 1. Distribution of gravity data (black dots) and GPS/levelling data (red dots) over Nairobi County and its environs 


\subsection{Evaluations}

To carry out the assessment of gravity anomalies, free-air gravity anomalies are obtained from EGM2008 and observed gravity data over the study area. The free-air gravity anomaly $\left(\Delta g_{F A}\right)$ at a point is given as,

$$
\Delta g_{F A}=g_{o b}+\delta g_{F A^{s}}+\delta g_{A C}-\gamma
$$

where $g_{o b}$ is the observed gravity, $\left(\delta g_{F A^{s}}\right)$ is the second-order free-air reduction, $\left(\delta g_{A C}\right)$ is a correction for the mass of the atmosphere and $\gamma$ is the normal gravity or theoretical gravity based on a selected reference ellipsoid (GRS80 in this case i.e. $\left.\gamma_{1980}\right)$.

The second-order free-air reduction (Heikanen and Moritz, 1967), the correction for the mass of the atmosphere (Wichiencharoen 1982a) and the normal gravity (Moritz, 1980a) are given respectively as (Equations 2, 3 and 4),

$$
\begin{aligned}
& \delta g_{F A^{s}}=\frac{2 \gamma_{e}}{a}\left(1+f+m-2 f \sin ^{2} \varphi\right) H-\frac{3 \gamma_{e}}{a^{2}} H^{2}, \\
& \delta g_{A C}=0.8658-9.727 \times 10^{-5} H+3.482 \times 10^{-9} H^{2}, \\
& \gamma_{1980}=978032.67715\left(1+0.0052790414 \sin ^{2} \varphi+0.0000232718 \sin ^{4} \varphi\right. \\
& \left.\quad+0.0000001262 \sin ^{6} \varphi+0.0000000007 \sin ^{8} \varphi\right),
\end{aligned}
$$

where $H$ is the orthometric height, $f$ is the polar flattening of the reference ellipsoid, $a$ is the length of the semi-major axis of the reference ellipsoid, $\gamma_{e}$ is the normal gravity at the equator, $\varphi$ is the geocentric latitude and $m$ is the ratio of centrifugal and gravitational forces at the equator.

Methods for computing geoid undulations and gravity anomalies from geopotential models are discussed by Heikanen and Moritz, 1967; Rapp, 1971; Smith, 1998; Torge, 2001, among other authors. 
The geoid undulation and free-air gravity anomaly implied by EGM2008 are obtained by Equations 5 and 6 respectively,

$$
\begin{gathered}
N_{E G M 2008}=N_{o}+C_{T}+\left[\frac{G M}{r \gamma} \sum_{n=2}^{n_{\max }}\left(\frac{a_{r e f}}{r}\right)^{n} \sum_{m=0}^{n}\left(\bar{C}_{n m} *_{n m} \cos m \lambda+\bar{S}_{n m} \sin m \lambda\right) \bar{P}_{n m}(\cos \theta)\right], \\
\Delta g_{E G M 2008}=\frac{G M}{r^{2}} \sum_{n=2}^{n_{\max }}\left(\frac{a_{r e f}}{r}\right)^{n}(n-1) \sum_{m=0}^{n}\left(\bar{C}^{*}{ }_{n m} \cos m \lambda+\bar{S}_{n m} \sin m \lambda\right) \bar{P}_{n m}(\cos \theta),
\end{gathered}
$$

where $N_{o}$ is the zero degree term, $C_{T}$ is a conversion term used to convert height anomaly (third term of Equation 5) into geoid undulation, $G M$ is the product of the universal gravitational constant and mass of the Earth, $r$ is the geometric distance between the centre of the Earth and the computation point, $a_{r e f}$ is a scaling parameter associated with a particular GGM (EGM2008 in this case), $\bar{P}_{n m}(\cos \theta)$ are the fully normalised associated Legendre functions for degree $n$ and order $m, \bar{C}{ }_{n m}$ and $\bar{S}_{n m}$ are fully normalised spherical harmonic coefficients after reduction by the even zonal harmonics of the reference ellipsoid and $n_{\max }$ is the finite maximum degree of a GGM (EGM2008 in this case).

The zero degree term $\left(N_{o}\right)$ is computed as (Heiskanen and Moritz, 1967),

$$
N_{o}=\frac{G M-G M_{O}}{R \gamma}-\frac{W_{O}-U_{O}}{\gamma},
$$

where $G M$ and $G M_{O}$ are related to the EGM2008 and reference system respectively, $W_{O}$ is the gravity potential of the geoid and $U_{O}$ is the normal gravity potential of the reference ellipsoid. The conversion term $C_{T}$ is obtained from a conversion model complete to degree and order 2160 (Pavlis 2012). The formulation of the conversion term $C_{T}$ (correction to height anomaly) is the same as the third term of Equation 5 (in the block bracket); hence there is no need for repeating it here.

The evaluation of EGM2008 is carried out in two ways. The first method determines standard deviation of the differences between GPS/levelling geoid undulations (obtained from observed GPS 
and precise levelling data) and geoid undulations implied by EGM2008 ( $\left.N_{\text {GPS/levelling }}-N_{\text {EGM 2008 }}\right)$.The second method determines standard deviation of the differences between free-air gravity anomalies (obtained from observed gravity data) and free-air gravity anomalies implied by EGM2008 $\left(\Delta g_{F A}-\Delta g_{E G M 2008}\right)$. The free-air gravity anomalies and geoid undulations implied by EGM2008 are computed at various spectral bands - 30 degrees interval between 0 to 180 degrees and 180 degrees interval between 180 to 2190 degrees.

\section{Results and Discussion}

The statistics of the differences between GPS/levelling and EGM2008 implied geoid undulations, and the differences between observed and EGM2008 implied free-air gravity anomalies are given in Table 1. The computations are done at 97 gravity and 18 GPS/levelling points. Figure 2 shows standard deviation of the differences between geoid undulations (obtained from ground observations and EGM2008) and free-air gravity anomalies (obtained from ground observations and EGM2008) while Figure 3 represents mean of the differences between geoid undulations and free-air gravity anomalies. Corrections to height anomaly obtained from a conversion model complete to degree and order 2160 are given in Figure 4. These corrections are used to convert height anomalies into geoid undulations.

Table 1. Statistics of the differences between geoid undulations and free-air gravity anomalies obtained from ground observations and EGM2008.

\begin{tabular}{l|cccc|cccc}
\hline & \multicolumn{3}{|l|}{ GPS/levelling - EGM2008 implied } & \multicolumn{4}{l}{ Observed - EGM2008 implied } \\
& \multicolumn{3}{|l}{ geoid undulations (m) } & & \multicolumn{3}{l}{ free-air gravity anomalies (mGal) } \\
\hline Degree & Min. & Max. & Mean & SD & Min. & Max. & Mean & SD \\
\hline 30 & 2.3980 & 2.8170 & 2.5680 & 0.1019 & -14.00 & 75.28 & 15.74 & 19.55 \\
60 & -1.1740 & -0.8311 & -1.0010 & 0.1002 & -40.13 & 50.06 & -10.11 & 19.79 \\
90 & -1.8020 & -1.3250 & -1.6020 & 0.1447 & -48.68 & 43.82 & -17.67 & 20.24 \\
120 & -1.4340 & -0.8776 & -1.1880 & 0.1736 & -42.89 & 51.47 & -11.02 & 20.50 \\
\hline
\end{tabular}


South African Journal of Geomatics, Vol. 5, No. 1, February 2016

\begin{tabular}{l|cccc|cccc}
\hline 150 & -1.4940 & -0.8886 & -1.2030 & 0.1965 & -44.12 & 53.22 & -10.95 & 21.07 \\
180 & -1.6530 & -0.7605 & -1.2380 & 0.2543 & -47.98 & 58.87 & -11.75 & 23.03 \\
360 & -1.2750 & -0.0764 & -0.8475 & 0.3074 & -32.74 & 84.77 & -1.77 & 27.67 \\
540 & -1.0170 & -0.2244 & -0.7157 & 0.1880 & -16.24 & 66.16 & 5.095 & 17.05 \\
720 & -0.9938 & -0.3208 & -0.7269 & 0.1472 & -15.00 & 59.64 & 3.216 & 13.18 \\
900 & -0.9492 & -0.4534 & -0.7293 & 0.1046 & -21.61 & 49.28 & 2.323 & 11.17 \\
1080 & -1.0070 & -0.4639 & -0.7263 & 0.1149 & -17.2 & 40.17 & 0.596 & 9.26 \\
1260 & -0.9650 & -0.5006 & -0.7259 & 0.1157 & -17.37 & 35.25 & -0.028 & 8.30 \\
1440 & -0.9425 & -0.4902 & -0.7322 & 0.1208 & -27.23 & 30.29 & -2.123 & 9.30 \\
1620 & -0.9514 & -0.4743 & -0.7346 & 0.1183 & -25.94 & 28.74 & -3.636 & 10.68 \\
1800 & -0.9302 & -0.4713 & -0.7342 & 0.1152 & -28.04 & 30.19 & -3.278 & 9.99 \\
1980 & -0.9163 & -0.4786 & -0.7300 & 0.1136 & -32.95 & 28.65 & -3.294 & 10.28 \\
2160 & -0.9262 & -0.4680 & -0.7297 & 0.1161 & -33.83 & 28.73 & -3.566 & 10.69 \\
2190 & -0.9254 & -0.4670 & -0.7297 & 0.1162 & -33.71 & 28.44 & -3.618 & 10.68 \\
\hline
\end{tabular}




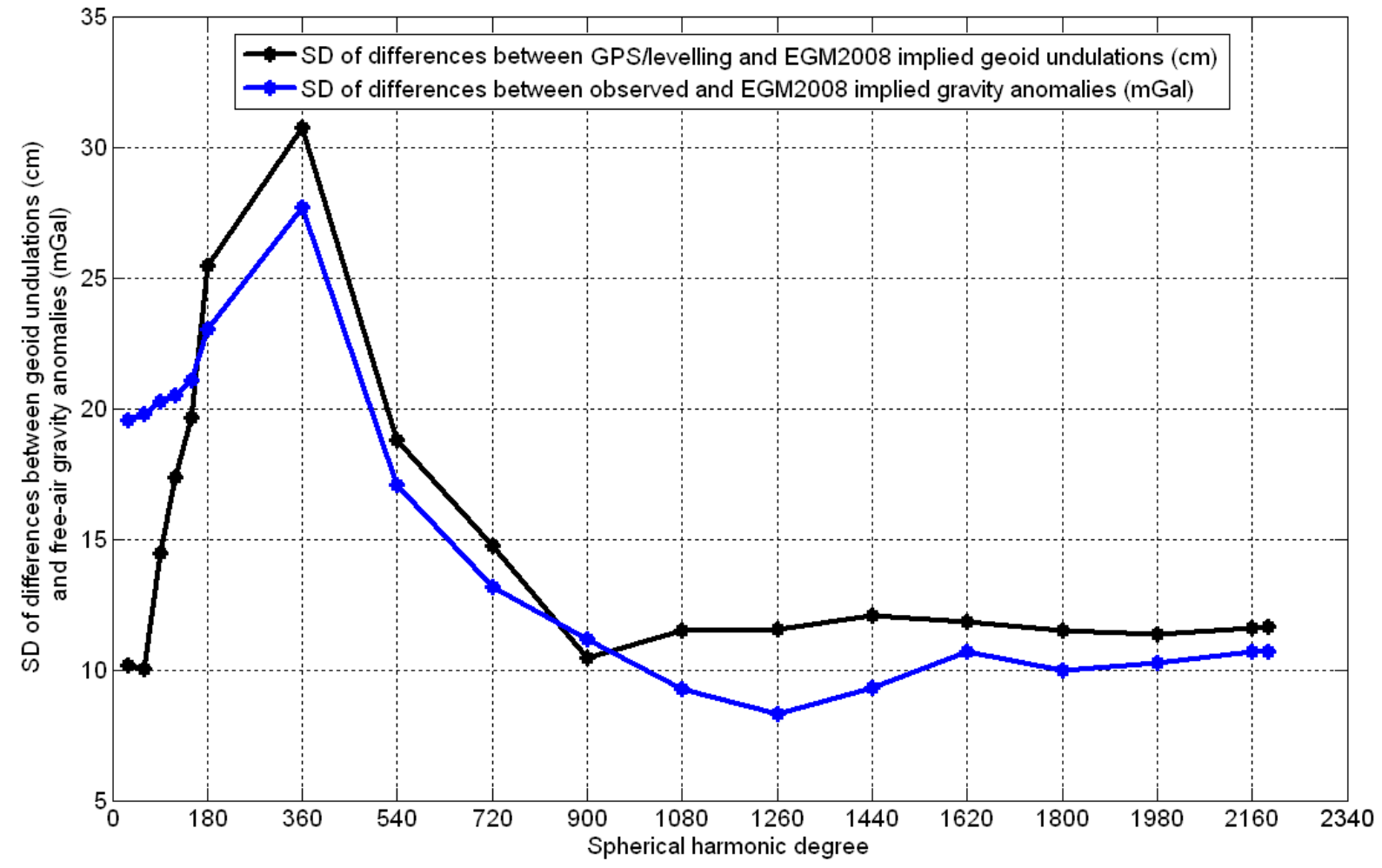

Figure 2. Standard deviation of the differences between geoid undulations and free-air gravity anomalies.

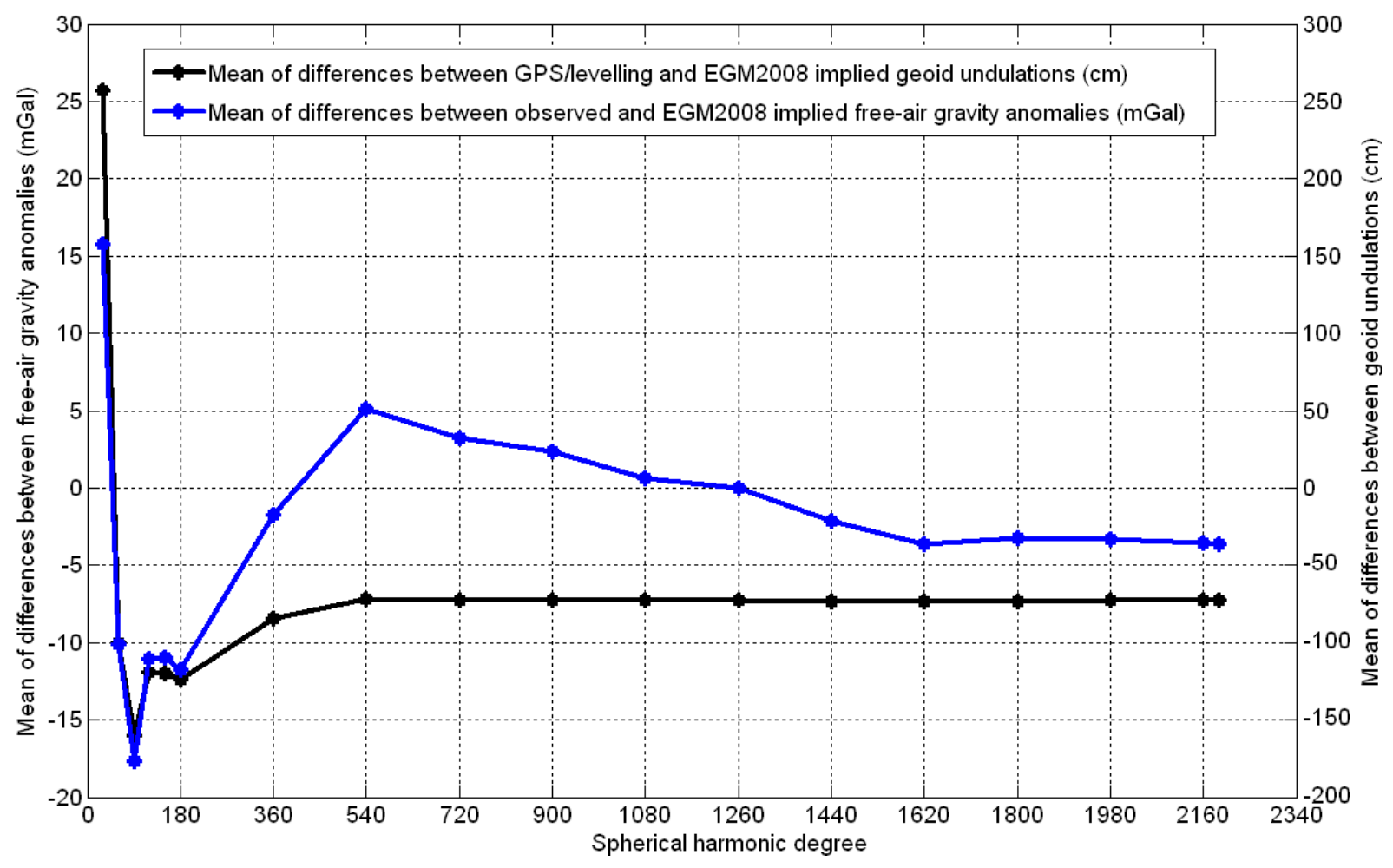

Figure 3. Mean of the differences between geoid undulations and free-air gravity anomalies. 


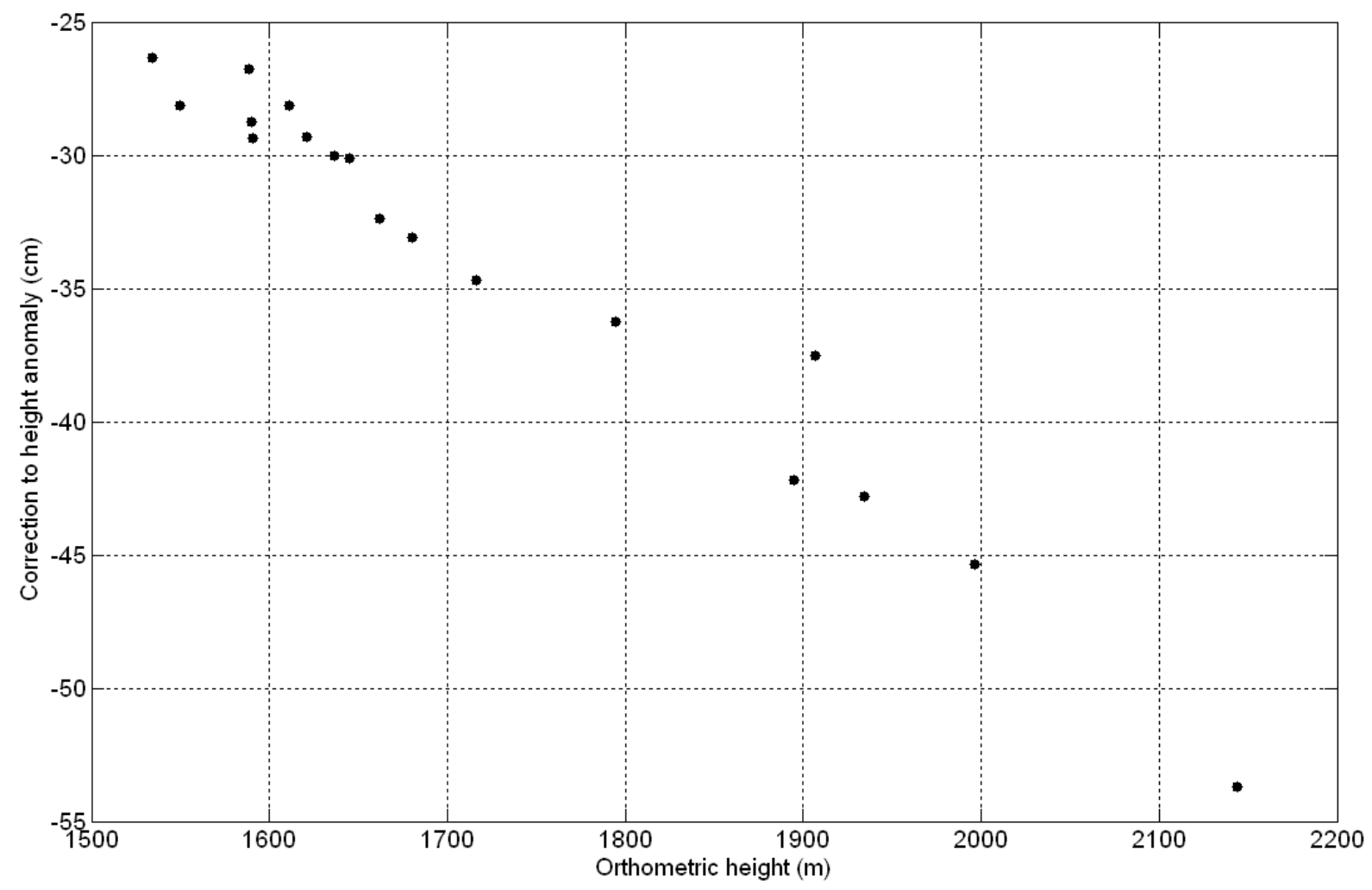

Figure 4. Correction to height anomaly to obtain geoid undulation.

The standard deviation of the differences between GPS/levelling and EGM2008 implied geoid undulations increases from 30 to 360 degrees and generally decreases from 360 to 2190 degrees. The same trend is obtained for the differences between observed and EGM2008 implied free-air gravity anomalies (Figure 2). However, the best solutions for geoid undulation and free-air gravity anomalies above 360 degrees are observed at 900 degrees $( \pm 10.5 \mathrm{~cm})$ and 1260 degrees $( \pm 8.3 \mathrm{mGal})$ respectively (Figure 2 and Table 1).

These results indicate that higher degrees beyond 900 and 1260 do not improve accuracy of geoid undulations and gravity anomalies respectively in the study area. This may also indicate that a number of point gravity data from the study area were not included in the development of EGM2008. There is a high potential for the development of an accurate geoid model in the study area and possibly Kenya by combining EGM2008 (truncated between 900 to 1260 degrees) with local terrestrial gravity data. An assessment of EGM2008 over the whole country (Kenya) would reveal the exact truncation point. This can only be done once necessary KENREF data sets have been processed and precise levelling carried out at the network points. 
The smallest offsets for geoid undulations and free-air gravity anomalies are observed at 540 degrees $(-71.6 \mathrm{~cm})$ and 1260 degrees $(-0.03 \mathrm{mGal})$ respectively (Figure 3 and Table 1$)$. A convergence solution can be seen in the gravity data. That is the best mean and standard deviation at 1260 degrees. Actually results from gravity anomalies (97 points) are statistically more reliable than geoid undulations (18 points) in the area of study. Also gravity data covers the study area better than GPS/levelling data (Figure 1).

Corrections to height anomalies vary from -53.7 to $-26.4 \mathrm{~cm}$ (Figure 4) with a mean and SD of 34.2 and $\pm 7.5 \mathrm{~cm}$ respectively. These corrections play a significant role in converting height anomaly to geoid undulation and they cannot be ignored in the determination of a geoid model from EGM2008. The standard deviation of the differences between gravimetric and GPS/levelling geoid undulations is $\pm 11.6 \mathrm{~cm}$. Figure 4 also shows that the conversion term (correction to height anomaly) is generally larger (in absolute terms) in high areas than low areas.

In comparison with EGM96 in the same area of study, there is an improvement in SD of the differences between gravimetric and GPS/levelling geoid undulations from $\pm 56.6 \mathrm{~cm}$ for EGM96 to $\pm 11.6 \mathrm{~cm}$ for EGM2008. This represents an improvement of $\pm 45.0 \mathrm{~cm}(80 \%)$. These results indicate that the performance of EGM2008 is 5 times better than EGM96 in the area of study.

\section{Conclusions}

An assessment of EGM2008 has been carried out using geoid undulations and free-air gravity anomalies over Nairobi County and its environs. The free-air gravity anomalies and geoid undulations implied by EGM2008 are computed at various spectral bands; 30 degrees interval between 0 to 180 degrees and 180 degrees interval between 180 to 2190 degrees. The data used include 18 GPS/levelling and 97 gravity points. The standard deviation and mean of the differences between GPS/levelling and EGM2008 implied geoid undulations are \pm 11.6 and $-73.0 \mathrm{~cm}$ respectively using a full expansion of EGM2008 (2190×2159). Similarly, the standard deviation and mean of the differences between observed and EGM2008 implied free-air gravity anomalies are \pm 10.7 and $-3.6 \mathrm{mGal}$ respectively. These results indicate a high potential for the use of EGM2008 in modelling a precise geoid model over the study area and possibly the whole of Kenya. Although there seems to be a large offset between EGM2008 (implied geoid undulations and free-air gravity anomalies) and observed local data.

The smallest standard deviations for the differences in geoid undulations and free-air gravity anomalies are obtained at 900 degrees $( \pm 10.5 \mathrm{~cm})$ and 1260 degrees $( \pm 8.3 \mathrm{mGal})$ respectively. The 
smallest means for the differences in geoid undulations and free-air gravity anomalies are obtained at 540 degrees $(-71.6 \mathrm{~cm})$ and 1260 degrees $(-0.03 \mathrm{mGal})$ respectively. It can be deduced that EGM2008 wave-lengths shorter than 1260 degrees do not improve geoid undulations and free-air gravity anomalies in the study area. This indicates that local gravity data, indirect effect from DEM and kernel modification(s) can be used to improve on EGM2008 omission errors beyond 1260 degrees in the study area. An initial high-resolution gravimetric geoid model over Kenya can be developed by combining EGM2008 and local gravity and topographical data sets.

\section{Acknowledgements}

Survey of Kenya provided GPS/levelling data. Gravity data was obtained from a catalogue of gravity measurements in Kenya, compiled at the department of Geology, Leicester University by Swain CJ and Aftab Khan M. The author would like to appreciate the two data sources. The author is also grateful to the two anonymous reviewers, for their constructive comments, suggestions and questions that have improved the paper.

\section{References}

Abeho, DR, Hipkin, R \& Tulu BB 2013, Evaluation of EGM2008 by means of GPS/Levelling in Uganda. South African Journal of Geomatics, vol. 3, no. 3, pp. 272-284.

Andersen, OB, Knudsen, P \& Berry PAM 2010, The DNSC08GRA global marine gravity field from double retracked satellite altimetry. Journal of Geodesy, vol. 84, no. 3, pp.191-199. doi: 10.1007/s00190-0090355-9

Aseno, JO 1995, Status of precise levelling and gravity measurements and their role in deformation monitoring in Kenya. Proceedings of the fourth international Symposium on recent crustal movements in Africa, edited by Aseno, JO, Ogao, PJ, Merry, CM, Chodata, MWL, Ng’onga, ER \& Riaroh DRO, November 28December 2, 1994, pp. 39-45.

Claessens, SJ, Featherstone, WE, Anjasmara, IM \& Filmer MS 2009, Is Australian data really validating EGM2008 or is EGM2008 just in/validating Australian data. Newton's Bulletin, pp. 207-251

Featherstone, WE \& Olliver, JG 2013, Assessment of EGM2008 over Britain using vertical deflections, and problems with historical data. Survey Review, vol. 45, no. 332, pp. 319-324.

Gachari, MK \& Olliver JG 1998, A high resolution Gravimetric Geoid of the Eastern Africa Region. Survey Review, vol. 34, pp. 421-435.

Heiskanen, WA \& Moritz H 1967, Physical Geodesy. Freeman, San Francisco. 
South African Journal of Geomatics, Vol. 5, No. 1, February 2016

Hirt, C, Marti, U, Bürki, B \& Featherstone WE 2010, Assessment of EGM2008 in Europe using accurate astrogeodetic vertical deflections and omission error estimates from SRTM/DTM2006.0 residual terrain model data. Journal of Geophysical Research, vol. 115: B10404.

Huang, J \& Véronneau M 2009, Evaluation of the GRACE-based global gravity models in Canada. Newton's Bulletin, pp. 66-72.

Loxton, J 1952, Geodetic levelling in Kenya. Survey Review, vol. 11, no. 86, pp. 338-346.

Mayer-Gürr, T 2007, ITG-Grace03s: The latest GRACE gravity field solution computed in Bonn, Joint International GSTM and SPP Symposium, October 15-17, 2007, Potsdam, Germany, http://www.geod.uni-bonn.de/itg-grace03.html

Moritz, H 1980a, Geodetic Reference System 1980. Bulletin Géodésique, vol. 54, pp. 395-405.

Newton's Bulletin 2009, Newton's Bulletin, no. 4, April 2009, Publication of the International Association of Geodesy and International Gravity Field Service, ISSN 1810-8555.

Odera, PA \& Fukuda, Y 2013, Towards an improvement of the geoid model in Japan by GOCE data: A Case study of the Shikoku area. Earth, Planets and Space, vol. 65, no. 4, pp. 361-366. doi:10.5047/eps.2012.07.005

Pavlis, NK, Factor, JK \& Holmes SA 2007, Terrain-related gravimetric quantities computed for the next EGM, Proceedings of the $1^{\text {st }}$ International Symposium of the International Gravity Field Service (IGFS), Istanbul, Turkey, Harita Dergisi, Special Issue 18, pp. 318-323.

Pavlis, NK, Holmes, SA, Kenyon, SC \& Factor JK 2008, An Earth Gravitational Model to Degree 2160: EGM2008, Presented at the 2008 General Assembly of the European Geoscience Union, Vienna, Austria, April 13-18, 2008

Pavlis, NK, Holmes, SA, Kenyon, SC \& Factor JK 2012, The development and evaluation of the Earth gravitational model 2008 (EGM2008). Journal of Geophysical Research, vol. 117: B04406.

Pavlis, NK, Holmes, SA, Kenyon, SC, Schmidt, D \& Trimmer R 2004, A Preliminary Gravitational Model to Degree 2160. Proceedings of GGSM 2004 IAG International Symposium. Porto, Portugal (ed. Jekeli C et al.), Springer, Heidelberg, pp. 18-23.

Pavlis, NK \& Saleh J 2004, Error Propagation with Geographic Specifity for Very High Degree Geopotential Models. Proceedings of GGSM 2004 IAG International Symposium, Porto, Portugal (ed. Jekeli C et al.), Springer, Heidelberg, pp. 149-154

Rapp, RH 1971, Methods for the Computation of Geoid Undulations from Potential Coefficients. Bulletin Geodesique, vol. 101, pp. 283-297.

Rapp, RH, Wang, YM, \& Pavlis NK 1991, The Ohio State 1991, Geopotential and Sea Surface topography harmonic coefficient models. Report No. 410, Department of Geodetic Science and Surveying, Ohio State University, USA. 
South African Journal of Geomatics, Vol. 5, No. 1, February 2016

Searle, RC 1970, A Catalogue of Gravity Data from Kenya. Geophysical Journal of the Royal Astronomical Society, vol. 53, no. 2, pp. 543-545. doi: 10.1111/j.1365-246X.1970.tb00159.x

Smith, DA 1998, There is no such thing as "The" EGM96 geoid: Subtle points on the use of a global geopotential model, in IGeS Bulletin No. 8, pp. 17-28, International Geoid Service, Milan, Italy

Swain, CJ 1979, Gravity and Seismic Measurements in Kenya, PhD. Thesis, Department of Geology, Leicester University, UK.

Swain, CJ \& Aftab Khan, M 1977, A Catalogue of Gravity Measurements in Kenya, Department of Geology, Leicester University, UK.

Swain, CJ \& Aftab Khan, M 1978, Gravity measurements in Kenya. Geophysical Journal of the Royal Astronomical Society, vol. 53, no.2, pp. 427-429.

Torge W (2001) Geodesy, 3rd ed., de Gruyter, Berlin, New York.

Wichiencharoen, C 1982a, FORTRAN programs for computing geoid undulations from potential coefficients and gravity anomalies. Internal Report, Department of Geodetic Science and Surveying, Ohio State University, Columbus, USA. 